\title{
LEITURA, EXPERIM ENTAÇÃO ARTÍSTICA E PRODUÇÃO TEXTUAL NAS SÉRIES INICIAIS DO ENSINO FUNDAMENTAL
}

\author{
Maria Emília Lubian ${ }^{1}$
}

Resumo: A produção textual baseada na leitura e expressão artística faz com que os alunos demonstrem interesse em divulgar suas idéias, isto porque envolve uma atividade prazerosa, há interlocutores reais para os textos produzidos e também 0 auxilio dos colegas para que os textos se tornem melhores na provocação de sentidos dentro do gênero escolhido. Dessa forma, relacionamos esta abordagem com a enunciação, visto que esta visão contempla o "ter o que dizer", "a quem dizer" e a descoberta de diferentes maneiras de "como dizer" na produção textual. As leituras de gêneros textuais narrativos e poéticos, observando as suas características de forma e conteúdo aplicadas na produção dos textos pelos grupos de alunos, bem como a divulgação destes em "histórias na sacola", em sarais, hora do conto, dramatização envolvendo as produções dos alunos e textos dos autores trabalhados, são apresentados neste trabalho em escola da rede municipal de ensino de Não-Me-Toque com crianças de terceira e quarta séries. Dessa forma, o nosso trabalho objetiva relacionar práticas de leitura e escrita, envolvendo a expressão artística desenvolvidas com alunos de séries iniciais do ensino fundamental.

Palavras-Chave: Leitura, Produção textual, Expressão artística.

Resumen: La produción textual baseada en la lectura y en la expresión artística hace con que los alumnos demonstren interés en divulgar sus ideas, eso porque envuelve una actividad prazerosa, hay interlocutores reales para los textos produzidos y también la ayuda de los compañeros para que los textos se tornem mejores en la provocación de sentidos dentro del género eligido. De esa forma, relacionamos esta abordage con la enunciación, una vez que esa visión contempla el "tener el que decir", "a quien decir" y la descoberta de diversas maneras de "como decir" en la produción de textos. Las lecturas de los géneros textuales narrativos e poéticos, mirando las sus características de forma y contenido en la produción de los textos por la clase de alumnos, bien como la divulgación de esas en "historias en la bolsa", en sarais, hora del cuento, dramatizaciones de las produciones de los alumnos e textos de los escritores estudiados, son apresentados en este trabajo en la escuela de la rede municipal de ensino de Não-Me-Toque con chicos de las clases tercera e quarta. Así, el nuestro trabajo objetiva interrelacionar prácticas de lectura y escrita, envolvendo la expresión artística desenvolvidas con alumnos de las clases iniciales de la enseñanza primaria.

Palabras Lave: Lectura, Produción textual, Expresión artística.

1 M estre em Letras - Estudos Lingüísticos pela Universidade de Passo Fundo (UPF); Professora do Ensino Fundamental na Rede Municipal de Ensino de Não-Me-Toque, RS; Coordenadora da "Educação em (re)vista" da referida rede e professora da área sociolingüística do Magistério Público Estadual no Núcleo de Educação de Jovens e Adultos e de Cultura Popular de Carazinho, RS. Também é professora de cursos de pós-graduação pela Portal Faculdades, RS e Aupex-FACEL, SC; endereço eletrônioco: milalubian@ hotmail.com. 


\section{INTRODUÇÃO}

As grandes nações escrevem suas autobiografias em três manuscritos: 0 livro de história, o livro das palavras e o livro da arte (John Ruskin. Filósofo, crítico e historiador de arte britânico).

Bakhtin (2003), retomado por Geraldi (1993), afirma que todo enunciado deve possuir uma razão para ser produzido, uma vez que, a partir da finalidade, pode-se construir um texto na escola ou para a escola, construindo-se, assim, uma produção textual ou uma redação. Contudo, vêem-se ainda exercícios de escrita que não evidenciam esse fator, fazendo com que o estudante não saiba por que escreve.

Este artigo apresenta o resultado de uma experiência escolar, vinculada ao projeto "História na Sacola" desenvolvido na EMEF Santo Antônio pela quarta série do ensino fundamental do turno da tarde, com a colaboração da quarta e terceira séries do turno da manhã. Este projeto visa o desenvolvimento de práticas de leitura, produção textual e divulgação destas por meio da expressão artística, refletindo sobre a promoção da escrita como uma produção de texto na escola e não apenas de uma redação.

\section{A FINALIDADE DA PRODUÇÃO TEXTUAL NA ESCOLA SEGUNDO A PERSPECTIVA DA ENUNCIAÇÃO}

Para Bakhtin (2003, p. 281), um dos elementos essenciais para a totalidade acabada do enunciado, que permite a possibilidade de responder é "o intuito, o querer-dizer do locutor", ou seja, a finalidade. Para o autor, independente do tipo de enunciado, o interlocutor capta, compreende e sente o querer dizer do locutor. Nas aulas, em muitas ocasiões, a produção é determinada pelas propostas presentes nos livros didáticos e a finalidade da produção textual, não fica clara para o aluno, fazendo com que este não saiba por que escreve. Noutras ocasiões, não há clareza quanto à intencionalidade que precisa ser contemplada nos textos de forma que o aluno não vê uma função comunicativa para seu texto, a não ser cumprir esta tarefa solicitada pela professora. A produção resultante desse tipo de exercício apresenta um tratamento superficial do tema e a falta de posicionamento do autor.

Bakhtin (2003) aponta que, o intuito (elemento subjetivo) entra em combinação com o objeto do sentido (objetivo) para formar uma unidade indissolúvel. Logo, a partir da junção do subjetivismo do indivíduo com o objeti- 
vo geral da escrita, forma-se o enunciado (unidade indissolúvel). Embora, o intuito deva apresentar as marcas individuais do sujeito, o que é possível constatar em textos de alunos é a falta de posicionamento ou expressão de seus pontos de vista.

Para Lerner (2002), o processo de produção de textos é bem mais que um exercício, sendo através dele a expressão do pensamento, por isso, lança um desafio aos professores:

o desafio é promover a descoberta e a utilização da escrita como instrumento de
reflexão sobre o próprio pensamento, como recurso insubstituível para organizar
e reorganizar o próprio conhecimento(...)". O desafio é, em suma, combater a
discriminação que a escola opera atualmente, não só quando cria o fracasso ex-
plícito daqueles que não consegue alfabetizar, como também quando impede
aos outros - os que aparentemente não fracassam - chegar a ser leitores e pro-
dutores de textos competentes e autônomos. O desafio que devemos enfrentar,
nós que estamos comprometidos com a instituição escolar, é combater a discri-
minação desde o interior da escola; é unir nossos esforços para alfabetizar todos
os alunos, para assegurar que todos tenham oportunidades de se apropriar da
leitura e da escrita como ferramentas essenciais do processo cognoscitivo e de
crescimento pessoal (LERNER, 2002, p. 28-29).

Na prática escolar, com relação à produção de textos, as aulas precisam aproximar a escrita tal como ela ocorre nas situações cotidianas dos alunos na escola e extra-escolares. Caso contrário, o aluno pode não saber o que dizer nem como, pois escrever sobre o que não se identifica, ainda mais com a preocupação em uma estrutura formal em relação à apresentação do seu texto, se torna inviável. Esta prática descaracteriza-se do objetivo da linguagem que é estabelecer relação entre os indivíduos e os textos falados ou escritos. Revela não a dificuldade do aluno em se expressar, mas sim a dificuldade do professor em instaurar práticas de linguagem dialógicas para haver produções textuais com marcas de autoria pelo grupo. Segundo, Lerner (2002, p. 18), se faz necessário fazer da escola "uma comunidade de escritores que produzem seus próprios textos para mostrar as suas idéias, para informar sobre fatos que os destinatários necessitam ou devem conhecer [...]".

A partir das discussões respeito dos conhecimentos produzidos historicamente pelo homem e veiculados por textos e de experiências coletivas, não pela assimilação destas informações, mas através do questionamento, da relação com a vida da transformação destas em conhecimentos é que se verifica uma prática dialógica de produção textual. A partir do diálogo é possível expressar as idéias através da produção de textos orais e escritos, tendo em vista que a produção é um processo e não um produto final. Todo o processo que envolve discussões, debates, pesquisas, leituras de diferentes gêneros que 
culminam na produção escrita são bastante viáveis, mas o mais importante nisso é o "para quê" dessas práticas. Segundo, Koch (1998, p.26), o texto acontece a partir da interação: "[...] o texto pode ser concedido como resultado parcial de nossa atividade comunicativa, que compreende processos, operações e estratégias que têm lugar na mente humana, e que são postos em ação em situações concretas de interação social". Porque, segundo Citelli (2003, p. 11), "estruturar um texto, integrando os vários níveis de sentidos, não é tarefa fácil, e a reflexão só ganhará eficácia se vier acompanhada de experiências e fatos significativos." Ao contrário de uma prática monológica de linguagem, em que para tudo o que se tem a dizer existe uma expressão apropriada, adequada, à espera de seu usuário e que desvaloriza as variações lingüísticas, o dialogismo vem restaurar a verdadeira função da linguagem que é a interação. Ao instituir uma prática intersubjetiva, que leve em conta a reflexão, será possível resgatar um discurso mais pessoal, mais autêntico de nossos alunos que se sentirão capazes de se expressar como autores. Quando o aluno/autor passa a conhecer de perto, na sua materialidade, o leitor de seus textos, pode debater suas idéias, começa a pensar mais concretamente num interlocutor para a sua produção escrita.

Na perspectiva dialógica, a compreensão é obtida através da negociação de sentidos entre locutor e interlocutor, é através da interlocução que os sentidos e a própria linguagem se constituem, visto que os sujeitos não são sempre os mesmos e a própria interlocução molda-os num processo evolutivo constante. Isso ocorre porque novas informações vão sendo incorporadas e reajustadas às anteriores e, através disso, vão reconstruindo o próprio sujeito. Por isso, se faz necessário observar estratégias visando o caráter dialógico da linguagem, tendo em vista um interlocutor real. Assim, uma prática pedagógica baseada na interação, facilita ao educando encontrar as ferramentas de que precisa para, ao reconhecer o seu interlocutor, fazer uso das qualificações pertinentes para desenvolver um discurso eficaz e ao alcance do outro.

Nesta perspectiva, Geraldi (1995, p. 136) faz uma diferenciação entre "produção de texto" e "redação", afirmando que: "nesta, produzem-se textos para a escola; naquela produzem-se textos na escola." Redação, para o autor, é um texto escrito sobre um tema proposto (ou imposto) pelo professor em que 0 aluno deve pôr em prática as regras gramaticais aprendidas. 0 exercício de redação é artificial, simulado, pois o texto não possui interlocutor e, portanto, não se configura por uma interação. A redação é uma atividade isolada em que se privilegia a forma, em detrimento do conteúdo. 0 aluno precisa mostrar que sabe escrever, e, por isso, preenche a folha em branco com palavras bonitas, agradáveis aos olhos do professor. A voz do aluno é calada, para em seu 
lugar, emergir a linguagem institucionalizada, conforme aponta Geraldi (1995). Assim, a redação não é trabalhada como uma prática social, pois a escola, em vez de possibilitar ao aluno um espaço para experiências pessoais, apresenta atividades que correspondem a "episódios de reprodução", priorizando exercícios gramaticais ou registro de conteúdos previstos.

Para deixar clara a distinção entre redação e produção textual, Geraldi (1995) apresenta algumas condições importantes para se produzir textos. Segundo o autor, é necessário que se tenha "o que dizer", "uma razão para dizer", que "o locutor se constitua como tal" e que "saiba escolher estratégias adequadas", de acordo com suas necessidades para a escrita. Para tanto, é preciso que o professor permita ao aluno que se constitua como sujeito de suas produções, de seus discursos e, que realmente produza seus textos dentro de uma situação real de comunicação, sabendo para quem dizer, sobretudo, 0 que dizer, utilizando, conforme destaca 0 autor, de estratégias adequadas para tal. Nesta perspectiva, são levadas em consideração as funções da escrita, as variações lingüísticas, a intencionalidade e a imagem do interlocutor, que pode ser real ou virtual. A escrita deixa de ser um mero exercício escolar, para adquirir um caráter dinâmico e processual, no qual o aluno se constitua como um sujeito ativo, passando a estabelecer uma real interação com seu interlocutor.

Produção de textos, ao contrário do "exercício de redação", é um processo dinâmico, de interação. É uma atividade em que, na opinião de Geraldi (1995, p. 136) o sujeito articula, aqui e agora, um ponto de vista sobre o mundo, vinculado a uma forma discursiva de maneira natural com o que se tem a dizer. Nesse aspecto, o texto é visto como um processo em que os sujeitos concretizam seus discursos, em que estabelecem interlocução, cientes da real função da escrita nas suas diversas situações de uso. É uma atividade dialógica, em que a linguagem é vista como forma de interação humana, em que 0 aluno saiba de fato "o que dizer", "para quem dizer" e "como dizer." Em outros termos, a produção de textos é uma atividade em que os sujeitos produzem discursos que se concretizam nos textos. Nesta atividade, quando um tema é proposto, há um levantamento de idéias relacionadas ao assunto, com discussões que possibilitem argumentações a favor ou contra as idéias enfocadas, sem controle ou diretividade pelo professor, para haver o desenvolvimento da reflexão do aluno em torno da escrita. Nesse sentido, nas produções, aparece a heterogeneidade de vozes que não reproduzem simplesmente a palavra dita pela escola ou as palavras alheias, mas a palavra do próprio aluno.

Em consonância com as idéias de Geraldi $(1995,2001)$, não se pressupõe que os alunos tenham ou não dom para a produção, mas são orientados para 
adquirir uma capacidade comunicativa, tanto no que se refere ao domínio dos mecanismos básicos da linguagem, quanto à postura crítica da realidade. 0 trabalho pedagógico não se realiza em função de um programa preestabelecido; ele acontece no cotidiano escolar, levando em conta as necessidades dos alunos na construção de conhecimentos. Sendo assim, o texto não é visto como produto, mas como um processo que precisa ser explorado, exposto, valorizado e vinculado aos usos sociais. Quanto ao professor, não se impõe como avaliador e juiz dos textos dos alunos, mas como um representante do leitor a que 0 texto se destina. Ele age como um interlocutor, encarando o aluno como sujeito de seu discurso. Com esse procedimento o professor questiona, sugere, provoca reações, exige explicações sobre as informações ausentes no texto, contrapõe à palavra do aluno, refutando, polemizando, concordando e negociando sentidos mediante as pistas deixadas no texto. Tudo isso, para que a produção textual do aluno evolua em todos os níveis e alcance, de forma satisfatória, o efeito de sentido proposto por ele, sendo que este possa se sentir valorizado ao ter o seu modo de pensar sobre a realidade, divulgado a diferentes interlocutores.

\section{A PRODUÇÃO TEXTUALA PARTIR DA LEITURA E DA EXPERIM ENTAÇÃO ARTÍSTICA}

0 gosto por estudar está presente nas primeiras séries escolares, pois nestes anos a arte e o lúdico fazem parte do cotidiano escolar. É nestes momentos que o educando tem a possibilidade de expressar sua interioridade de uma maneira prazerosa e espontânea e a arte manifesta-se como forma de expressão nas aulas. Por isso, despertar o gosto pela leitura nas séries iniciais se torna um trabalho natural. As histórias, as lendas, as poesias, as músicas, a expressão plásticas são apreciadas e necessárias, pois a partir da motivação que trazem ao aluno, ajudam a despertar a sua capacidade discursiva. Ou seja, a literatura passa a ter a função de despertar novas experiências aos jovens leitores, conforme aponta Caldin (2001) sobre a literatura infantil na contemporaneidade. Para a autora, a literatura deve facilitar a compreensão e desvelar dos dogmas que a sociedade impõe através do questionamento destes através da leitura. A literatura infantil contemporânea, segundo Caldin (idem), oferece uma nova concepção do texto escrito que é aberto a múltiplas leituras e faz da literatura um suporte para a compreensão do mundo. A literatura ao abrir espaço para o questionamento, favorece a reflexão que transpassa tanto a interpretação da obra quanto da realidade do aluno. 
Levando em conta esta possibilidade apresentada pela literatura infantil, torna-se mais fácil redigir uma história se houver a leitura, a dramatização, a ilustração de narrativas do gênero a ser produzido. Ainda mais, se as histórias são lidas e comentadas no grupo, cada um expondo numa roda de conversa 0 que mais Ihe chamou a atenção, os personagens e suas ações, as idéias apresentadas na obra. Para referenciar esta idéia, citamos Citelli (2003, p. 11) que afirma a respeito da produção textual: "estruturar um texto, integrando os vários níveis de sentidos, não é tarefa fácil, e a reflexão só ganhará eficácia se vier acompanhada de experiências e fatos significativos." M ais adiante, a autora expõe, a partir de sua experiência, maneiras de proceder em atividades de leitura e escrita em sala de aula: "o ponto de partida para o desenvolvimento de cada proposta de redação é um trabalho de sensibilização que proporciona aos participantes um mergulho prático, pois participativo e reflexivo, no trabaIho de redigir" (CITELLI, 2003, p. 20). A autora afirma que a necessidade de a produção acontecer com a participação de todos, incluindo o professor, sendo que todos produzem e lêem os seus textos e os dos demais, através de um processo de interação através do signo escrito. Citelli (idem, p. 20) destaca como exemplo desta interação, a organização de varais de poesias musicados, rápidas apresentações de textos, para que a escola possa ler a produção dos colegas.

Concordamos que a sensibilidade artística está presente entre as crianças e adolescentes com a mesma intensidade com que estão descobrindo seus sentimentos. A música e seus gêneros, a poesia, a dança, as artes visuais estão ali registradas na sua expressão, no seu material escolar, nos seus ídolos. 0 teatro é uma forma de ser outro, de viver outros sentimentos, de conhecer outros mundos mesmo que seja só na platéia. Quando estão envolvidos com 0 trabalho de montar uma apresentação teatral, ou improvisar um texto, estão ali lendo e relendo, inventando enredos e falas, assumindo o discurso de um personagem. Para o aluno que não é acostumado a ler como atividade escolar, para conhecer seus ídolos lê, decora suas letras de música, revistas que falam de sua vida, ao notar o sexo oposto, lê mensagens e poesias românticas e as copia e volta a ler em seus cadernos, agendas, até mesmo faz acrósticos, inventa frases, poesias, que escreve em cartas para quem está apaixonado ou mostra para amigos. Ao assistirem a filmes, novelas, seriados, idealizam os seus ídolos, imaginam-se no lugar destes, observam todos os detalhes e depois recriam novas situações para estes na sua mente. Imaginam-se atores, cantores famosos, imitam seu modo de ser, inserem no seu vocabulário o que estes falam. Ou seja, os alunos lêem e muito, mas coisas que Ihes trazem interesse, não como imposição escolar. 
A poesia é muito apreciada pelos alunos, pela sua sonoridade e jogo de palavras que mexem com sua imaginação. Ler, reconhecer diferentes poesias, decorar os textos e dizer de foram dramatizada, desperta tanto a vontade de ler mais quanto de inventar outras poesias. As crianças adoram ver a natureza, as cores, os sentimentos expostos na poesia, tanto como adoram ouvir música. Adoram ouvir músicas e dançar. Ao unir a música e a poesia num sarau, por exemplo, entre alunos do ensino fundamental em que realizamos a experiência, os alunos demonstraram muito interesse nestas atividades, sempre sugerindo e querendo fazer mais. A música, a poesia, o teatro, as artes plásticas unidas numa apresentação resultou em trabalhos muito interessantes. Inclusive, despertou a vontade de produzir textos para serem inseridos nas apresentações junto com os textos de poetas estudados pelo grupo. Enfim, acreditamos que as artes e sua linguagem vêm a contribuir no processo de ampliação da capacidade de expressão dos alunos tanto na fala como na escrita. Torna as aulas mais alegres e dinâmicas, o lúdico volta a fazer parte da aprendizagem, reforçando a interação verbal entre os indivíduos, os textos e as artes, conforme apontam.

Para M icarello e de Freitas (2002), a leitura e escrita estimuladas a partir de elementos culturais para além dos muros da escola, que possam encontrar nestes instrumentos uma fonte de prazer e entretenimento. Também a leitura cumpre um papel social ao favorecer o despertar da consciência cidadã, promovida pelo debate entre os leitores a respeito dos sentidos presentes, conforme explica Caldin (2001, p. 10) sobre a formação de leitores. Para a autora, a leitura enquanto oportunidade de enriquecimento e experiência é primordial na formação do indivíduo e do cidadão, porque aquele que lê é capaz de meIhor desempenho em suas atividades e apresenta melhor aptidão para enfrentar os problemas sociais.

É importante para a produção, o conhecimento do que se quer dizer e isso só é possível pela leitura, promovida através do diálogo entre os autores e diferentes textos. Ninguém escreve do nada como um "Adão bíblico, só relacionado com objetos virgens ainda não nomeados, aos quais dá nome pela primeira vez", conforme aponta Bakhtin (2003, p. 300). Para o autor, na realidade da interação lingüística "cada enunciado é pleno de ecos e ressonâncias de outros enunciados com os quais está ligado pela identidade da esfera da comunicação discursiva" (BAKHTIN, op. cit., p. 297). A leitura dos diferentes textos a respeito do tema a ser trabalhado, o diálogo entre eles e sobre eles, irá embasar a produção do texto. No entanto, somente esta perspectiva não basta. Para o sujeito, aqui reconhecido como 0 aluno, se sentir um autor, precisa ter claro para si quem será o seu leitor. Este não pode ser apenas a figura 
solitária de um professor, que o lê principalmente como avaliador de sua capacidade de expressão, dando-Ihe uma nota. Segundo Bakhtin (2003), é preciso levar em conta um elemento fundamental do enunciado que é o seu direcionamento a alguém, o que irá definir a construção do seu enunciado tanto pelo seu conteúdo, gênero e estilo.

Sendo assim, há uma motivação para a escrita se o sujeito reconhece o seu leitor, também favorece a linguagem a ser empregada neste contexto. A possibilidade de interação lingüística que reconhecemos na fala, deve estar presente na escrita também, o que favorecerá a escolha das palavras, o gênero a ser empregado nas diferentes situações de interlocução, favorecendo a expressão da intencionalidade, conforme aponta Bakhtin (2003). Para o autor, reconhecemos os diversos gêneros do discurso na expressão oral, como a poesia presente nas músicas, a opinião de uma pessoa sobre um assunto, o relato da vida dos mais velhos, a narração de fatos do noticiário, o drama, a comédia, a ficção nos filmes, nas novelas, nos desenhos animados. No entanto quando não existe o contato com estas formas nos livros, "em termos teóricos podemos desconhecer a sua existência" (BAKHTIN, 2003, p. 282, grifo do autor). Então, para que seja possível se expressar com proficiência, fazendo uso dos diversos gêneros, é preciso ter o contato com estes na escrita. Também com 0 hábito da leitura somos capazes de perceber semelhanças deste texto com outros, pela intertextualidade ali presente e também verificar a intencionalidade do autor.

A produção textual é favorecida pela leitura, no sentido que esta última proporciona o contato com diferentes discursos presentes nos gêneros textuais, favorece através do debate a reflexão tanto sobre o conteúdo quanto sobre a forma de apresentação dos discursos nos diferentes textos e intencionalidades dos autores. As leituras, o debate proporciona a análise do que estas dizem para si enquanto sujeito da interação verbal, para que ao produzir um texto seja possível perceber o seu conhecimento do gênero aliado ao seu conhecimento de mundo. Ainda nos referimos a Caldin sobre a leitura e a formação do cidadão: "A leitura, portanto, dá voz ao cidadão, no sentido de que sua interpretação pode gerar a transformação do mundo," (2001, p. 11). Ou seja, a consciência crítica também se forma pela leitura e 0 debate do que é lido, 0 que se reflete na produção textual. Retomando palavras de Bakhtin (2003) sobre a discursividade, ninguém faz uso da palavra sem ter um motivo, sem direcionar-se para alguém, caso contrário este se torna um exercício sem sentido. Os sentidos dos enunciados nascem da interação entre os indivíduos e textos, numa constante interação que constitui seus discursos. 


\section{RELATO DE EXPERIÊNCIA, "HISTÓRIA NA SACOLA"}

Para relacionar práticas de leitura e escrita dos gêneros narrativo e poético, envolvendo a expressão artística desenvolvidas com alunos de séries iniciais do ensino fundamental, organizamos junto a nossa comunidade escolar 0 projeto: "história na sacola" em que os professores de 3a e 4a séries desenvolvem como seus alunos. Este projeto visa despertar o gosto pela escrita através da expressão artística, através da ilustração dos textos produzidos, pela contação de histórias ou dramatização dos textos lidos e produzidos nos gêneros trabalhados com os grupos nas outras turmas de séries iniciais, favorecendo a divulgação tanto das leituras como das produções dos alunos.

Este trabalho surgiu a partir da discussão de dados do SAEB e SAERs, provas nacionais e estaduais que mediram o nível de interpretação e produção textual dos alunos, de $4^{a}$ e 8 séries e de $2^{a}$ e 5 séries. Observamos que nossa escola obteve níveis abaixo da realidade das outras escolas municipais e estaduais de Não-M e-Toque. A partir de um debate em reunião de formação entre as professoras, começamos a pensar em atividades que pudessem reverter este quadro e, mais do que preparar para os próximos testes, discutimos possibilidades de favorecer 0 aprendizado dos usos da linguagem nos diferentes contextos, para que os alunos sejam capazes de ler com competência, compreendendo as intencionalidades presentes nas obras. Para que com as leituras, também possa ser despertado o desejo de produzir textos, tendo em vista a existência de leitores reais para as suas produções.

A Biblioteca ganhou um espaço próprio, reorganizado, com a aquisição de diferentes obras de literatura e de pesquisa para educação infantil até as séries finais do ensino fundamental. 0 nome eleito para este ambiente entre a comunidade escolar foi "O mundo da imaginação", o qual parece apropriado pelas possibilidades que podem ser criadas a partir deste espaço junto aos alunos. Cada professor iniciou um trabalho efetivo de troca de idéias sobre as obras lidas pelos alunos. Também há professoras que têm carga horária quinzenal para a realização de hora do conto com alunos de séries iniciais e também empréstimo semanal de livros de literatura infantil e infanto-juvenil. Os alunos das séries iniciais têm participado dos momentos de divulgação e discussão de leituras, na hora do conto dirigida por professoras ou mesmo organizando a contação de histórias na biblioteca para as outras turmas, com 0 auxílio da professora da oficina de teatro. Também estamos organizando entre as professoras a contação de histórias por professores para professores e comunidade adulta do bairro e do município para estimular a divulgação de obras e leitura também entre familiares e professores. 
Para relacionar uma prática de leitura, produção e divulgação de textos pelos alunos da quarta série, podemos mencionar o estudo das histórias de assustar do folclore popular, em que aparecem os elementos "mistério, seres assustadores como fantasmas, mula-sem-cabeça, lobisomem, casas e florestas mal assombradas, cemitério". Trabalhamos em sala de aula histórias folclóricas brasileiras registradas em livros e também resgatamos as histórias que a comunidade conta, principalmente por avós. Os alunos contaram em sala de aula estas histórias e comparamos com os livros, o que tinha de semelhante e diferente. Por exemplo, o lobisomem é uma lenda que se acredita, inclusive que pessoas narram que chegaram a ver de longe sua sombra. Também narram a possibilidade de lugares serem mal assombrados e de ter percebido a presença de fantasmas. A partir das leituras e das histórias contadas pela comunidade, foram recontadas em sala de aula pelos alunos algumas das histórias de terror. Os alunos organizaram em pequenos livros ilustrados suas histórias que foram emprestados às outras turmas na sacola feita pelo grupo. Também houve um momento em que os alunos se prepararam e foram nas outras turmas fazer uma sessão de "contos de assustar", com cortinas fechadas para escurecer 0 ambiente e criar um clima.

Em seqüência ao nosso trabalho, neste ano letivo, estamos organizando com a quarta série a contação coletiva de histórias, em que os textos de autores da biblioteca ou produzidos pela turma, são trabalhados para serem apresentados nas outras séries do ensino fundamental e também na educação infantil. A contação envolve a expressão dramática e o canto para que as histórias possam entusiasmar o público, provocando o despertar da imaginação tanto de quem conta como de quem ouve a história.

\section{CONCLUSÃO}

Sabemos que a produção textual é um processo e que temos alunos em nossa turma que tiveram poucas oportunidades de escrita nas outras séries e que, agora na quarta, estão começando a sua condição de produtores de textos, por isso algumas destas histórias ainda não apresentaram muitas marcadas da intenção do autor, apesar de ser de interesse do grupo o tema destas narrativas. Também destacamos que a produção foi realizada em vários momentos, primeiro de troca de idéias sobre o gênero, seus elementos, leituras realizadas, conversas sobre estas leituras e com pessoas da comunidade. No momento da produção dos textos, cada aluno debateu com a professora e colegas seu texto, o que poderia colocar para aperfeiçoar suas idéias, discutindo a lógica do texto, o que queria dizer e o como dizer de maneira a ser enten- 
dido pelos leitores. Nestes aspectos, foi observada a organização lógica das idéias e a maneira de expressá-las tanto na estrutura do texto, como na pontuação, ortografia e a letra. Num outro momento, foi organizado o livro, o que seria dito e ilustrado em cada página. Noutro momento, como seriam apresentadas as histórias para as outras turmas organizando o modo como uma "história de assustar" seria contada. Depois disso, foi feita uma avaliação das produções, quanto à forma de apresentação dos livros e a contação das histórias para as outras turmas. Enfim, a produção e divulgação das idéias nos textos é um processo que leva tempo e empenho, sendo que a cada produção há uma evolução da condição de leitor e produtor de texto pelos alunos no gênero trabalhado, pois estamos procurando evidenciar um processo de "produção textual" na escola e não de redação conforme aponta Geraldi (2001). Isto porque produzir é um processo que exige evolução constante.

\section{REFERÊNCIAS}

BAKHTIN, M. Estética da criação verbal. 4. ed. São Paulo: Martins Fontes, 2003.

CALDIN, Clarice Forkamp. A função social da leitura da literatura infantil. Centro de Ciências da Educação - Universidade de Santa Catarina, documento eletrônico, www.encontrosbibli.ufsc.br/Edicao_15/caldin_funcaosocial.pdf. Santa Catarina, 2001. p. 1-12.

CITELU, Beatriz. A produção e leitura de textos no ensino fundamental: poema, narrativa, argumentação, v. 7. 3. ed. Coord.: CITELLI, Adilson; CHIAPPINI, Ligia. Aprender e ensinar com textos. São Paulo: Cortez, 2003.

GERALDI, J. W. Portos de Passagem. 3. ed. São Paulo: Martins Fontes, 1995.

GERALDI, J. W.. Escrita, uso da escrita e avaliação. In: GERALDI, W. J. (Org.). 0 texto na sala de aula. São Paulo: Ática, 2001, p.127-131.

KOCH, I. V. A inter-ação pela linguagem. 4 ed. São Paulo: Contexto, 1998.

KOCH, I. V. 0 texto e a construção dos sentidos. São Paulo: Contexto, 2003.

LERNER, Delia. Ler e escrever na escola: o real, o possível e o necessário. Porto Alegre: ARTMED, 2002.

MICARELLO, Hilda Aparecida Linhares da Silva; FREITAS, Lucélia Rodrigues de. Os sentidos produzidos por crianças e adolescentes pelas suas experiências com leitura e escrita na escola. In: FREITAS, M aria Teresa A.; COSTA, Sérgio Roberto. (Org.). Leitura e escrita na formação de professores. Juiz de Fora: UFJF, 2002. 